\title{
Cultura Cultura
}

Revista de Historia Teeria das deleas $\quad$ Revista de História e Teoria das Ideias

Vol. 23 | 2006

Ideia(s) de Tempo(s)

Time in Augustan poetry

\section{O tempo na poesia augustana}

\section{Luís Cerqueira}

\section{CpenEdition}

Journals

Edição electrónica

URL: http://journals.openedition.org/cultura/1348

DOI: $10.4000 /$ cultura.1348

ISSN: 2183-2021

\section{Editora}

Centro de História da Cultura

\section{Edição impressa}

Data de publição: 1 Janeiro 2006

Paginação: 111-118

ISSN: 0870-4546

\section{Refêrencia eletrónica}

Luís Cerqueira, "O tempo na poesia augustana », Cultura [Online], Vol. 23 | 2006, posto online no dia 25 fevereiro 2014, consultado a 04 maio 2019. URL : http://journals.openedition.org/cultura/1348 ; DOI : 10.4000/cultura. 1348

Este documento foi criado de forma automática no dia 4 Maio 2019

(c) CHAM - Centro de Humanidades / Centre for the Humanities 


\title{
Time in Augustan poetry
}

\section{O tempo na poesia augustana}

\author{
Luís Cerqueira
}

1 É lugar comum dizer-se que o tempo da Antiguidade Clássica se distingue do tempo cristão pelo seu carácter circular, enquanto o tempo cristão, nomeadamente a partir de Agostinho, é pensado de folma linear e teleológica, Através da análise de alguns textos poéticos da literatura latina do período augustano, mostraremos que a realidade é mais variada e complexa. Se quisermos enunciar uma diferença fundamental entre a concepção cristã do tempo e a concepção greco-romana, esta será antes a noção de um início absoluto do tempo, definido nas primeiras palavras da Bíblia: "No princípio criou Deus o Céu e a Terra", ${ }^{1}$ início absoluto que de modo nenhum se encontra nas cosmogonias clássicas. Antes do princípio de Hesíodo, Ovídio e Lucrécio existe sempre algo, ainda que informe e caótico.

2 O tempo dos poetas é uma expressão particular da experiência humana do tempo, e, mais do que uma especulação filosófica ou noção científica, é uma percepção subjectiva marcada pelo sensibilidade individual.

3 Todavia esta experiência pessoal do tempo enquadra-se e depende parcialmente de um conjunto das crenças religiosas e teorizações filosóficas que enformam a atitude destes homens face ao tempo, que estão sempre subjacentes e são por vezes explicitadas.

4 A cultura romana vai buscar à cultura grega as suas grandes concepções do tempo, como esta depende em grande parte de noções orientais. E os filósofos gregos especularam longamente sobre este assunto.

5 Para os materialistas gregos, Demócrito e Epicuro, o tempo é a forma da matéria em movimento. $\mathrm{O}$ tempo não é um incorpóreo independente, mas um acidente particular de alguns estados, que são eles próprios acidentes: associamos o tempo ao dia e à noite $\mathrm{e}$ às suas partes constituintes, como aos sentimentos e à sua ausência, ao movimento e ao repouso, considerando que um acidente particular destes é que chamamos tempo.

6 A perspectiva epicurista do tempo, popularizada em Roma por Lucrécio, define então o tempo como algo que não existe em si mesmo, uma realidade inseparável da matéria: "O 
tempo não existe em si mesmo, mas ganha o seu sentido a partir das próprias coisas". ${ }^{2}$ Está limitado, confinado, pela nossa percepção do mundo, com a efemeridade inerente a esta percepção e às coisas em si mesmas. Não existe para lá de nós.

7 Do ponto de vista individual o tempo é uma noção que se extrai da evolução da natureza e sobretudo de nós próprios, e isso significa que o tempo é o nosso caminhar para a morte, pois o seu aspecto gerador e criador, enquanto algo de fundamental, diz respeito apenas aos outros. A nossa consciência de que o tempo nos gerou é ponto assente, dado que não nos proporciona inquietude para reflectir, uma vez gerados, sendo sobrepujada pela nossa consciência actual de que caminhamos para a morte, e então o tempo autonomizase como nosso inimigo.

Inimigo intimidante, onda que nos enrola na sua voragem, a cada um de nós, e nos devora, como Cronos devorava os seus filhos.

Outra perspectiva é a de um tempo com existência autónoma, exterior à matéria, imagem móvel da eternidade, forma eterna, anterior à experiência e independente dela, concepção platónica expressa no Timeu que Cícero recupera, dizendo que o tempo é uma parcela da eternidade, com o carácter determinado e específico de ano, mês, dia e noite. ${ }^{3}$ O tempo é uma entidade, com a sua lógica e organização, ainda que misteriosa. Esta concepção, que se encontra já no Pitagorismo, é a base da concepção do tempo no estoicismo romano.

Os poetas augustanos confrontam-se com o seu tempo vivido enquadrados por estas duas concepções filosóficas fundamentais e antagónicas, uma materialista e outra idealista.

11 Horácio é, nas suas palavras, "um porco da vara de Epicuro". Quando o objectivo da vida é a busca do prazer individual, o tempo apresenta-se ao poeta, limitado ao seu pequeno universo de interesses pessoais, como medida de degradação do seu próprio corpo. Assim nos diz Horácio que "ligeiros os anos se nos escapam", fugaces labuntur anui, e que a velhice, as rugas e a morte se lançam sobre nós inexoravelmente. 0 seu deslizar escapa ao nosso controlo, não podendo nós fazer nada para o evitar. É o ensinamento insistente da Ode, 2, 14:

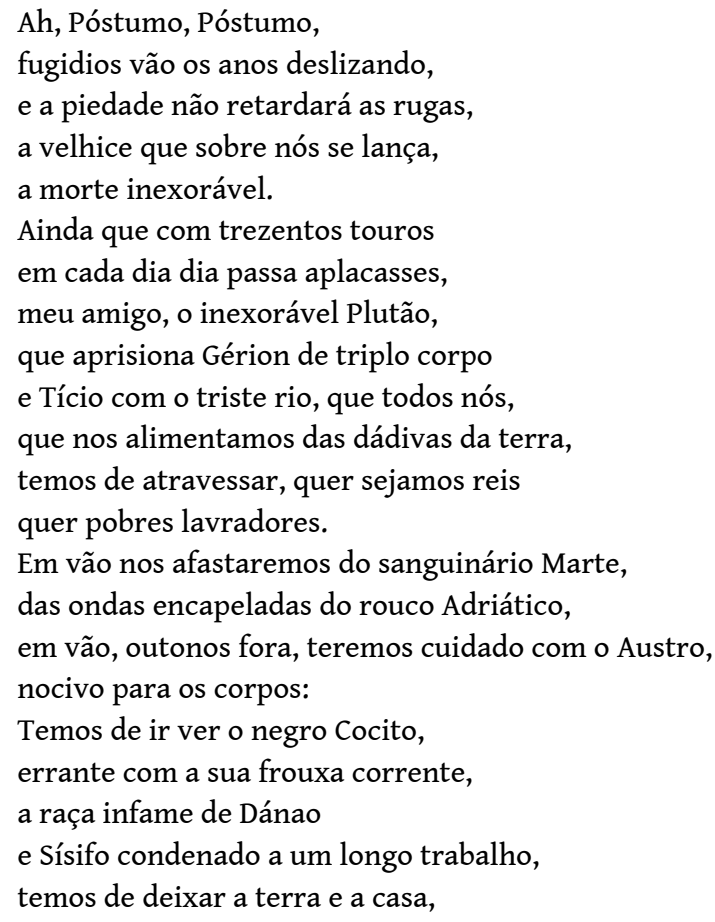




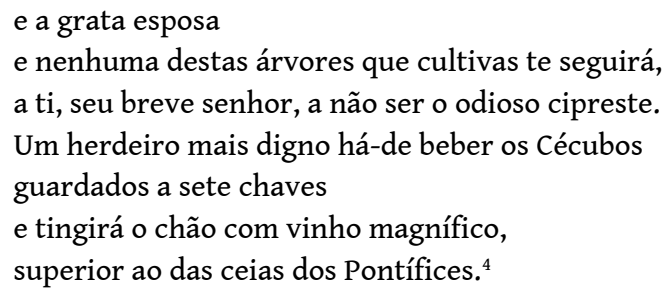
necessidade de fruição do momento, do carpe diem, do agarrar o instante. $O$ instante que se opõe à perspectiva da continuidade.

A famosa ode 1, 11 responde assim à angústia da anterior:

"Sê sensata, filtra os teus vinhos,

limita alongada esperança a breve espaço:

enquanto falamos, já terá fugido o odioso tempo,

colhe o instante, acreditando o menos possível no dia de amanhã". ${ }^{5}$

O verbo labor, deslizar, e o verbo fugio, fugir, são a expressão de um tempo que nos escapa, num movimento que não controlamos e cuja fluidez nos é perniciosa e adversa. Daí a adjectivação do tempo como inuidus, inuidiosus. Detestável.

Horácio fala do tempo obsessivamente, desesperadamente. Se a verificação do seu caracter inexorável é admonição para o colher do instante, este nunca é jubiloso, porque o tempo continua lá, para lá do instante pontual, e não cessa de nos devorar. Mesmo no prazer está presente o tic-tac do relógio, que impede a plenitude do fruir. Mesmo "enquanto falamos já terá fugido o odioso tempo".

A mesma concepção e vocabulário se podem encontrar em Ovídio:

"Deslizam os tempos e vamos envelhecendo com os anos sorrateiros e fogem, sem freio que os retarde, os dias."6

Outra elemento que nos poetas epicuristas é usado para exprimir esta inexorabilidade é a imagem do tempo como um rio:

"Também os próprios tempos deslizam com um movimento constante, tal como um rio, e com efeito não pode parar nem o rio nem a leve hora, mas como a onda inpele a outra onda, a primeira empurra a da frente e a outra a essa."7

18 E ainda:

"Desliza a ocultas e zomba de nós o volátil tempo, tal como desliza o célere rio."8 O tempo é mesmo agressivamente voraz, consumindo os seus filhos:

"Ó tempo devorador das coisas e tu detestável velhice, vós tudo destruis. Com os dentes do tempo consumis tudo pouco a pouco, com uma lenta morte." 9 O vocabulário, as imagens do rio que nada pode suster, e uma adjectivação negativa do tempo, a ideia de que o tempo nos devora exprimem uma autonomização do tempo como nosso inimigo, ao invés da noção teórica epicurista de que o tempo não existe exteriormente à matéria.

21 Há nestes poetas, em Horácio especialmente, uma angústia do tempo, moderna, aflitiva, inesperada num tempo que ainda não é, como o nosso, medido ao segundo pela exactidão opressiva dos nossos relógios, mas antes ritmado pelo tranquilo nascer e pôr do sol. E é nesta angústia de vítimas do tempo que estes poetas ultrapassam na sua expressão artística o enquadramento filosófico epicurista nos diz que o tempo nem sequer existe fora de nós e das coisas. 
Há no entanto uma forma de escapar à destruição do tempo devorador, a produção de uma obra literária cuja perfeição mereça sobreviver e alcançar a imortalidade. Só a obra sobra, o resto soçobra, no dizer de um outro poeta. Horácio diz ter construído um monumento que não poderá ser destruído pela chuva, pelo vento, ou pela sucessão dos anos e a passagem das eras. ${ }^{10}$ Consolo todavia insuficiente para iluminar de alegria a produção poética destes autores.

Para a Antiguidade Clássica o tempo nem sempre é circular. 0 tempo dos epicuristas não só não é circular, mas não chega sequer a ser linear, é um angustiado segmento de recta, obcecado pelo seu termo. É um spatium breuis, em que a delimitação é acentuada pelo

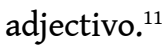

Os poetas elegíacos, epicuristas também eles, projectam num tempo passado, num ambiente de simplicidade rural, religiosa e campestre, a felicidade de uma Idade do Ouro em que não havia nem guerras nem ambição, causas da infelicidade do tempo presente, Idealização suave e melancólica de um passado romano, mais do que uma fuga melacólica para o tempo mítico da idade do Ouro.

Este tempo é um tempo-espaço, um refúgio criado pela imaginação literária. A angústia da iminência da morte leva-os a rejeitar o seu tempo e a realidade da guerra e a procurarem refúgio num tempo literário, tal como a Arcádia do bucolismo é um espaço utópico. Este tempo mítico dos elegíacos partilha com o tempo mitológico da Eneida, legitimador e fonte de sentido do tempo histórico de Augusto, da nobreza de um tempo ideal.

Para os Estóicos o tempo é diferente. Em oposição a um tempo que escorrega descontroladamente, surge um tempo que roda, uoluitur, verbo que indica um movimento circular, e implica uma regularidade controlada. Isso nos ensina o estóico Séneca.

"O tempo gira, com uma ordem determinada, ainda que de forma misteriosa". ${ }^{12}$

7 É esta noção estóica que fundamenta a experiência vergiliana: se o tempo nos transcende, isso não é fonte de angústia, uma vez que há nele um sentido profundo.

28 É certo que, do ponto de vista individual, o tempo acarreta geração e destruição, mas isso não implica a revolta contra algo que não só não controlamos e nos destrói mas que não tem um sentido em si mesmo.

Méris, na Bucólica IX, diz que o tempo tudo leva, até a memória, mas outros cantarão, diz com bonomia. ${ }^{13} \mathrm{O}$ escoar da ampulheta da vida faz parte de uma ordem razoável.

30 "Cada um tem o seu dia marcado, é breve e irreparável para todos o tempo de vida, mas expandir o renome por meio de feitos heróicos, isso é a tarefa que cabe à valentia", diz Júpiter, ao perceber que se aproxima o destino fatal de Turno. ${ }^{14}$

31 A inevitabilidade da morte não é fonte de angústia pessoal, mas é acompanhada pela aceitação da nossa hora e pela consciência de que esta deve ser vivida com grandeza heróica, ao serviço do bem comum. 0 tempo vergiliano não é um tempo pessoal, embora o indivíduo se insira no tempo, e por isso não é um tempo que destrói.

32 O tempo, concebido de uma forma que transcende o indivíduo para abarcar a história da humanidade, é visto nos antípodas do instante, do instante do prazer e do instante da vida humana, é visto na imensa sucessão de séculos do grande ano pitagórico. 0 tempo de Vergílio é cíclico, concepção de origem oriental e comum a outros povos antigos. 0 tempo não é apenas fonte de degradação, mas também suaviza e gera, o rodar do tempo permite 
até a esperança. Uma visão serena do universo no seu todo, serena porque desprendida do indivíduo e da sua contingência, serena porque existe uma ordem universal.

Vergílio é até optimista, discrepando da generalidade dos autores antigos, ao dizer que o tempo traz melhoramento e progresso:

"Muitas coisas o tempo e o labor da eras que mudam tornam melhores." 15

O texto mais elucidativo da visão vergiliana do tempo é sem dúvida a bucólica quarta. Neste poema, o nascimento e o crescimento de um misterioso menino traz consigo o regresso da idade do ouro, coincidente com o recomeço do grande ciclo. Neste tempo circular não há um começo da história, como no Cristianismo, mas um fim que é princípio, um momento do círculo que é o seu melhor momento, e que está prestes a regressar:

"Já chega a última idade da profecia de Cumas, nasce de novo a grande sucessão dos séculos, regressa a Virgem e os reinos de Saturno.... no teu consulado, Polião começará esta glória do tempo e começarão a avançar os grandes meses." ${ }^{16}$

Este tempo implica uma repetição dos acontecimentos.

"Haverá então um outro Mis, uma segunda nau Argo para transportar os heróis escolhidos. Haverá outras guerras e de novo será enviado para Tróia um valoroso Aquiles." 17

Estaremos uma vez mais aqui, o leitor desse lado, o texto deste, a reflectir sobre o tempo na literatura latina.

A intervenção do homem neste desenrolar do ciclo é nula, pois depende de forças que o transcendem.

Este é um tempo que está muito próximo, uma vez que o poeta afirma o seu desejo de ter vida e saúde para o celebrar no final da sua vida, um tempo que corresponde a uma ordem pré-estabelecida, mas que se espera ansiosamente:

"Em consonância com o imutável poder dos fados, as Parcas disseram aos seus fusos: Correi tais séculos!"18

O tempo, mais do que degradação ou progresso, é um regresso constante, A originalidade de Vergílio foi olhar para o desenrolar do tempo como um motivo de esperança e alegria, situando-se à entrada da casa de partida, o que lhe permite uma alvoroçada alegria: "Vê como tudo se alegra com o século vindouro!"19

O que é caracteristicamente pessoal em Vergílio, ainda que apoiado numa concepção filosófica estóica, mais, o que é espantoso em Vergílio, é este alento, esta capacidade de esperança num poeta que presenciou um tempo de carnificina e crueldade e que ainda assim é capaz não só de sonhar com um outro tempo, mas de afirmar a iminência do paraíso. Porque é de um futuro imediato que nos; fala, está já aí, pois o poeta deseja ter vida bastante para cantar esta Idade de Outro. Mas o elemento pessoal é secundário, o que é relevante é a sua afirmação confiada num tempo melhor que inevitavelmente virá. Também para nós é bom acreditar nisso. 


\section{NOTES}

1. Genesis, 1,1 .

2. Tempus autem per se non est, sed rebus ab ipsis consequitur sensus, Lucrécio, De rerum natura, I, 459-463. E ainda materia in assiduo motu, I, 995; rerum motus, I, 463.

3. tempus est ... pars quaedam aeternitatis, cum alicuius annui, menstrui, diurni nocturni spatii certa significatione., Cicero, De inu., 1, 26.

4. Eheu fugaces, Postume, Postume,/ labuntur anui nec pietas moram! rugis et instanti senectae/ adferet indomitaeque morti; // non si trecenis quotquot eunt dies;/ amice, places inlacrimabilem/ Plutona tauris, qui ter amplum Geryonem Tityonque tristi// compescit unda, scilicet omnibus,/ quicumque terrae munere uescimur, / enauiganda, siue reges / siue inopes erimus coloni.// Frustra cruento Marte carebimus/ fractisque rauci fluctibus Hadriae,/ frustra per autumnos nocentem / corporibus metuemus Austrum; // uisendus ater flumine languido/ cocytos errans et danai genus/ infame damnatusque longi/ Sisyphus Aeolides laboris/ linquenda telus etdomus et placens/ uxor, negue fumou quas colis arborum/ te praeter inuisas cupressos/tulla breuem dominum sequetur. // Absumete heres Caecuba dignior/ seruata centum clauibus et mero/ tinguet pauimentum superbo/ pontificum potiore cerzis. Horácio, Com., 2, 14.

5. ...sapias, uiva fiques et spatio breui/ spem longam reseces. Dum loquimur fugerit/ inuida aetas: carpe diem, quam minimum credula postero., Horácio, Carm., 1, 11.

6. tempora labuntur, tacitisque senescimus amnis et fugiunt, freno non remorante, dies, Ovídio, Fasti, VI, 771-2.

7. Ipsa quoque adssiduo labuntur tempora motus non secus ac flumen; negue enfim consistere flumen nec leuis hora potest, sed ut unda impellitur unda urguetur prior uenientem, urget priorem, Ovídio, Met., 15, 179185.

8. Labitur occulte fallitque uolatilis aetas

Vt celer admissis labitur amnis, Ovídio, Am., I, 8, 49-5

9. Tempus edax rerum, tuque inuidiosa uetustas omnia destruitis, uitiataque dentibus aeui paulatim lenta consumitis omitia morte, Ovídio, Met., 15, 234.

10. annorum series et fuga temportun, Horácio, Carm., 3,30.

11. breuis spatium uitae, Ovídio, Met., III, 124; sapias, uiva fiques et breui spatio spem longa reseces, Horácio, Carm., 1,10.

12. uoluitur tempus, rata quidem lege, sed per obscurum.

13. Omnia fert aetas, animum quoque,Vergílio, Eclog., 9,51 .

14. Breue et irreparabile tempus est omnibus uitae, Vergílio, Aen., 10,467.

15. Num passo em que usa dies por tempus: Multa dies uariique labor mutabilis aeui rettulit in melius, Vergflio, Aen., II, 425-426.

16. Vitima Cumaei uenit iam carminis aetas;/ magnus ab integro saeclorum nascitur ordo. / Iam redit et Virgo, redeunt Saturnia regna,/ iam noua progenies caelo demittitur ab alto., Vergílio, Eclog., IV, 4-7 (tradução da Professora Maria Isabel Rebelo Gonçalves, tal como as restantes citações da IV Bucólica).

17. alter erit tum Tiphys et altera quae uehat Argo/delectos heroas; erunt etiam altera bella/ atque iterum ad troiam magnus mittetur Achilles., Vergílio, Eclog., IV, 34-6.

18. talia saecla suis dixerunt currite fusis/ concordes stabili fatorum numine Parcae, Vergílio, Eclog., IV, 46-7.

19. Aspice uenturo laetantur ut omnia saeclo, Vergílio, Eclog., IV, 52. 


\section{ABSTRACTS}

Estuda-se a percepção do tempo nos poetas augustanos, analisando-se as duas perspectivas fundamentais, a dos poetas epicuristas (Horácio, Ovídio, poetas elegíacos) e a dos poetas estóicos (Vergílio). Verifica-se que, embora dependam da teorização filosófica de origem grega, manifestam características pessoais que vão para além dela.

We have studied the perception of time in augustan poets, namely the two main perspectives, one of epicurist poets (Horace, Ovidius, elegiac poets) the other of a stoic poet (Vergil). We verify that, although they do depend on philosophical teorization of greek background, they show personal features that surpass those speculations.

\section{INDEX}

Keywords: augustan literature, time perception, Vergil, Horace

Palavras-chave: literatura augustana, percepção do tempo, Vergílio, Horácio

\section{AUTHOR}

\section{LUÍS CERQUEIRA}

Centro de Estudos Clássicos. Universidade de Lisboa

Professor Auxiliar da Faculdade de Letras da Universidade Clássica de Lisboa, instituição em que tem ensinado as cadeiras de Latim e Música e Literatura, colaborando também com a Universidade Católica no ensino do Latim. Doutorado em Literatura Latina em 2000, com a tese A música especulativa na tradição hispânica medieval. Pervivência e transformação da herança clássica, tem-se interessado pela teoria musical antiga e medieval, tendo traduzido o De Musica de Boécio e publicado artigos em que se cruzam e mutuamente esclarecem a sua formação literária e musical. No campo da épica latina publicou artigos e traduções de textos, nomeadamente o De Raptu Proserpinae de Claudiano e a Eneida de Vergílio, esta de parceria com colegas da Faculdade de Letras. 